\title{
Evolution of texture and microstructure during thermo-mechanical processing in ultrathin low carbon steels
}

\author{
Laura Guadalupe Castruita Ávila ${ }^{1}$, Francisco Garcia Pastor ${ }^{1}$, \\ Manuel de Jesus Castro Román ${ }^{1}$
}

\author{
${ }^{1}$ Centro de Investigación y de Estudios Avanzados del Instituto Politécnico Nacional (CINVESTAV-IPN), Department \\ of Metallurgical Engineering and Materials Science, Industria Metalúrgica 1062. Parque Industrial Saltillo-Ramos \\ Arizpe, C.P 25900, Ramos Arizpe Coahuila, México. \\ e-mail: 1.castruita@microestructura.org, francisco.garcía@ cinvestav.edu.mx
}

\begin{abstract}
In this research paper an analysis concerning the evolution of crystallographic texture during hot rolling processing of low carbon steel is presented. The study was performed on a steel sheet with an initial thickness of $1.9 \mathrm{~mm}$ used in the process of cold rolling. In order to assess the differences between tensile and compressive deformation, a $90^{\circ}$ cold bending was carried out in this specimen. Texture evolution analysis greatly helps to assess the effect of some mechanical properties, particularly formability. The material was annealed under different conditions of time and temperature using an inert atmosphere. The chemical composition was determined by optical emission spectrometry. The study of crystallographic texture present in this steel was performed using the electron backscatter diffraction (EBSD) technique by means of OIM (Orientation Imaging Microscopy) mapping, inverse pole figures and orientation distribution functions (ODFs). Electron diffraction Backscattered (EBSD) is a technique that allows to detect and analyze information crystallographic on the surface of a sample which is observed by scanning electron microscope (SEM). An analysis of the effect of processing parameters and differences between tensile and compressive deformation on the microstructure and crystallographic texture changes in these materials is presented. The results are discussed in terms of both the resulting anisotropy after the annealing treatment and the primary fibers founded by this technique.
\end{abstract}

Keywords: Annealing, EBSD, Crystallographic Texture, ODF 's.

\section{INTRODUCTION}

There is particular interest in the production of ultrathin (approximately 200 micrometers) steel sheets for specific applications in food packaging. Important parameters such as the deformation percentage and annealing characteristics must be carefully controlled in order to obtain a quality product with the required specifications. Interstitial free steels (IF) are recognized because of their excellent mechanical properties on deep drawing processes [1].

The evolution of the microstructure and final texture during the annealing process occurs because of recrystallization, which is considered as the formation of new grains from a deformed structure. Recrystallization starts at high-angle grain boundaries $\left(10-15^{\circ}\right.$ over) while the grain growth is driven by the stored energy results from forming. There is an important effect of manufacturing parameters of low carbon steels in the final texture, obtaining optimum anisotropy in ultrathin sheets used in the molding. During annealing, new nuclei in the grain boundaries are formed; a viable nucleus is one that is surrounded by a high angle grain boundary able to migrate through the deformed microstructure thus causing their growth [2].

During the deformation process, the dislocations are concentrated in areas of lower energy such as grains forming low angle subgrain, hence the microstructural changes occurred during annealing is related to the decrease in stored energy caused by the turnover mechanisms and the annihilation of defects in crystals [3-4].

By increasing the temperature new grains are generated, causing a decrease in the free energy and consequently a progressive increase in grain size [5-6]. 
A fine-tuned combination between cold deformation process and annealing makes it possible to obtain the ideal microstructure and thus the required mechanical properties [7-9].

Previous studies reported that depending on each material a minimum deformation is required to initiate recrystallization (1-5\%) [10-11].

An important feature which allows reasonable prediction of mechanical properties of materials is the finished product crystallographic texture. A common technique for texture quantitative analysis is EBSD (Electron Backscatter Diffraction) [12-13-14]. Texture is determined on the Euler space which is represented by a three dimensional view in the context of Bunge $\varphi_{2}=45^{\circ}$ at this point is possible to appreciate the most important textures components in angles $\varphi_{1}, \Phi$ and $\varphi_{2}$ [15-16-17]. The final texture of a material depends on the crystallographic preferred orientation of each grain after recrystallization.

The capacity and the degree of deformation of a sheet steel is the formability, this property must be strictly controlled during severe deformation to avoid the appearance of cracks without affecting the loss of strength of the material. The degree of formality of a sheet of steel depends on the texture you get at the end of the manufacturing process. Understanding the texture helps to relate the mechanical properties including single crystal. It is noteworthy that the art backscattered electron diffraction EBSD (electron backscattering difraction) allow the energy stored grain and grain crystallographic orientation.

As growth occurs, preferential grain textures known as fibers are formed. The texture of steel is generally defined by a complete $\gamma$ fiber and partial $\alpha$ fiber. A $\gamma$ fiber corresponds to fiber orientations of the grains constituting the steel for which $\{111\}$ planes of ferrite crystal lattice of match the rolling plane [18- 1920-21-22]. During the lamination process and subsequent annealing recrystallization occurs which is reflected by a change in the texture through the emergence of $\gamma$ and $\alpha$ fiber. The texture of a material in which the $\{111\}$ planes are parallel to the normal direction (denoted as $\{111\} / / \mathrm{ND}$ ), is referred as a $\gamma$ fiber texture. In steels, this kind of texture displays high formability in deep stamping processes. When the grains are oriented with their $\{110\}$ planes parallel to the normal direction $(\{110\} / / \mathrm{ND})$, the material is considered to display an $\alpha$ fiber texture. Steels displaying a strong $\alpha$ fiber texture are not favorably oriented for severe deformation processes [4-25]. The driving force of recrystallization is a function of the dislocation density high rate of deformation can result a high dislocation density [26].

Recrystallization is a phenomenon that despite being been studied for many years, is not yet fully clarified, in particular the crystallographic texture resulting from the recrystallization which requires additional studies to understand the factors that lead to the formation of certain crystallographic fibers. This is of particular importance in ultrathin steel sheets such as the ones analyzed in this paper.

\section{MATERIALS AND METHODS}

The steel used in this study is a low carbon ferritic steel. The chemical characterization was determined by spark optical emission spectrometry. The chemical composition is detailed in Table 1.

Table 1: Chemical composition of the steel sheet used in the experiment (mass \%).

\begin{tabular}{lccccccccccc}
\hline $\mathrm{C}$ & $\mathrm{Si}$ & $\mathrm{Mn}$ & $\mathrm{P}$ & $\mathrm{S}$ & $\mathrm{Cr}$ & $\mathrm{Mo}$ & $\mathrm{Ni}$ & $\mathrm{Al}$ & $\mathrm{Cu}$ & $\mathrm{Ti}$ & $\mathrm{V}$ \\
\hline $\mathbf{0 . 0 4}$ & $\mathbf{0 . 0 0 8}$ & $\mathbf{0 . 1 5 4}$ & $\mathbf{0 . 2 9}$ & $\mathbf{0 . 0 1 5}$ & $\mathbf{0 . 0 2 2}$ & $\mathbf{0 . 0 0 3}$ & $\mathbf{0 0 2 4}$ & $\mathbf{0 . 0 2 0}$ & $\mathbf{0 . 0 3 2}$ & $\mathbf{0 . 0 0 1}$ & $\mathbf{0 . 0 0 3}$ \\
\hline
\end{tabular}

The study was conducted using sheets of $1.9 \mathrm{~mm}$ thick and $1 \mathrm{~cm}$ long, cold bent at $90^{\circ}$. This hot rolled sheet is used as the starting material for subsequent cold roll processing in order to obtain ultrathin sheets. The metallographic preparation began with grounding in fine granulometry $\mathrm{SiC}$ sandpaper of 2400 , using water as lubricant. The polishing was performed with Microcloth cloths using diamond paste $0.3 \mu \mathrm{m}$ and 0.1 $\mu \mathrm{m}$. The final polishing was carried out with suspension of colloidal silica with a particle size of $0.4 \mu \mathrm{m}$ and polishing time of 35 minutes. Samples were attacked with Nital 3\% for 15 seconds, and then subjected to a cleaning process in an ultrasound cleaner. The annealing heat treatment was conducted under a nitrogen atmosphere at temperature of $670{ }^{\circ} \mathrm{C}$ with a heating rate of $10{ }^{\circ} \mathrm{C} / \mathrm{min}$, with soaking times of 900 and 1800 seconds. The characterization was performed on a microscope SEM, using the backscattered electrons technique. TSL EBSD technique OIM (Orientation Imaging Microscopy) was used to determine the evolution of texture and microstructure in each microscopic area of the sample. The ODF's representing Euler angles Bunge formalism were calculated coring the OIM software. Sample symmetry was set as orthotropic and calculation method used Harmonic series expansion, with a rank of 16 Gaussian smoothing $5^{\circ}$. 


\section{RESULTS AND DISCUSION}

The recrystallization process of steel during annealing heat treatment has been presented by two models: (a) oriented and (b) selective growth nucleation, increasing component density in $\{111\}<112>[20]$. Subjected to the tensile and compression achieved ultrathin film strengthened in $\{110\}$ planes and $\{111\}$ of a bcc typical material.

When a material is cold deformed there is a direct dependence between the crystallographic orientation of the microstructure and the stored energy during deformation. A recrystallized grain is considered one which has a substructure inside and grain boundaries have a large misorientation which can vary between $15^{\circ}$ and $20^{\circ}$ with respect to neighboring grains. This large misorientation between adjacent grains allows boundaries to have great mobility in growth [4]. Figure 1(a) shows the EBSD OIM maps of a sheet after $90^{\circ}$ bending. It is possible to observe the grains deformed in tensile and compressive areas, whereas in the central area the grains remain equiaxed. Figure 1 (b) show the evolution of texture of section the ODF's of $\Phi_{2}=0^{\circ}-360^{\circ}$ of the bent speciment without any heat treatment
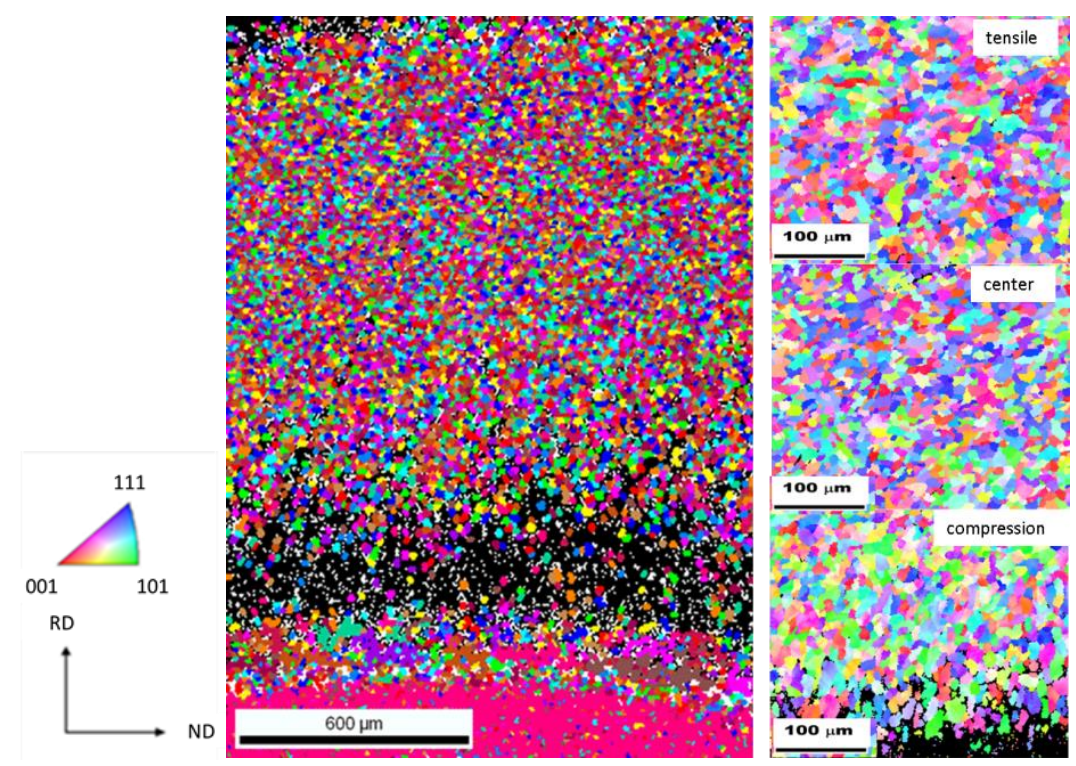

(a)
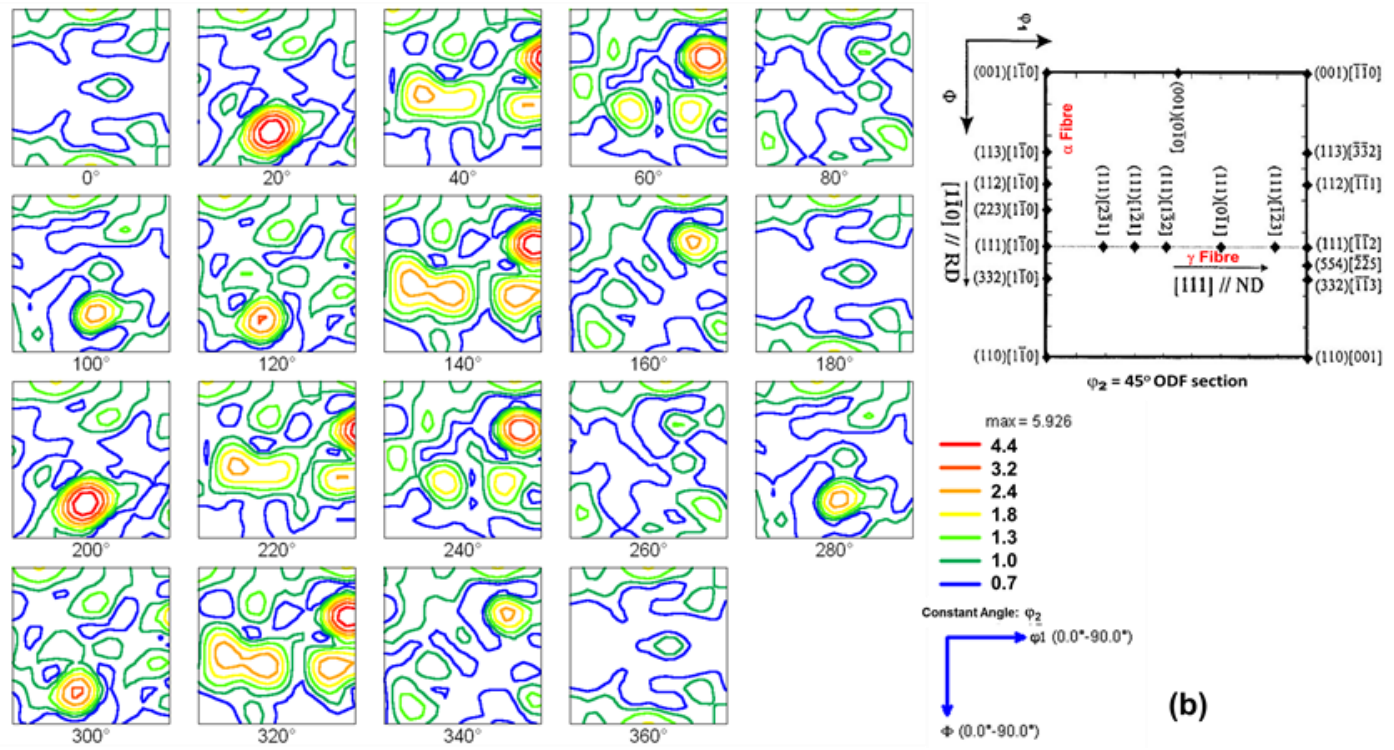

(b)

Figure 1: Figure 1(a) OIM maps of the bent speciment without any heat treatment, showing the differences between the tensile, compressive and central (undeformed) areas, (b) show the evolution of texture of section the ODF's of $\Phi_{2}=0^{\circ}$ $360^{\circ}$ of the bent speciment without any heat treatment. Anex components in $\varphi 2=45^{\circ}$ section of ODF representing main orientation. 
Figure 2 (a) represents the steel before thermal annealing treatment. Grains deformed in the top and bottom due to the compression and tensile were observed, while in the center equiaxed grains that were not affected by the applied external forces can be identified. After 900 seconds of $670^{\circ} \mathrm{C}$ heat treatment, the deformed grains begin the process of recovery and recrystallization (Figure. (2b)). in figure 2 (c) it is easy to detect the grain growth.

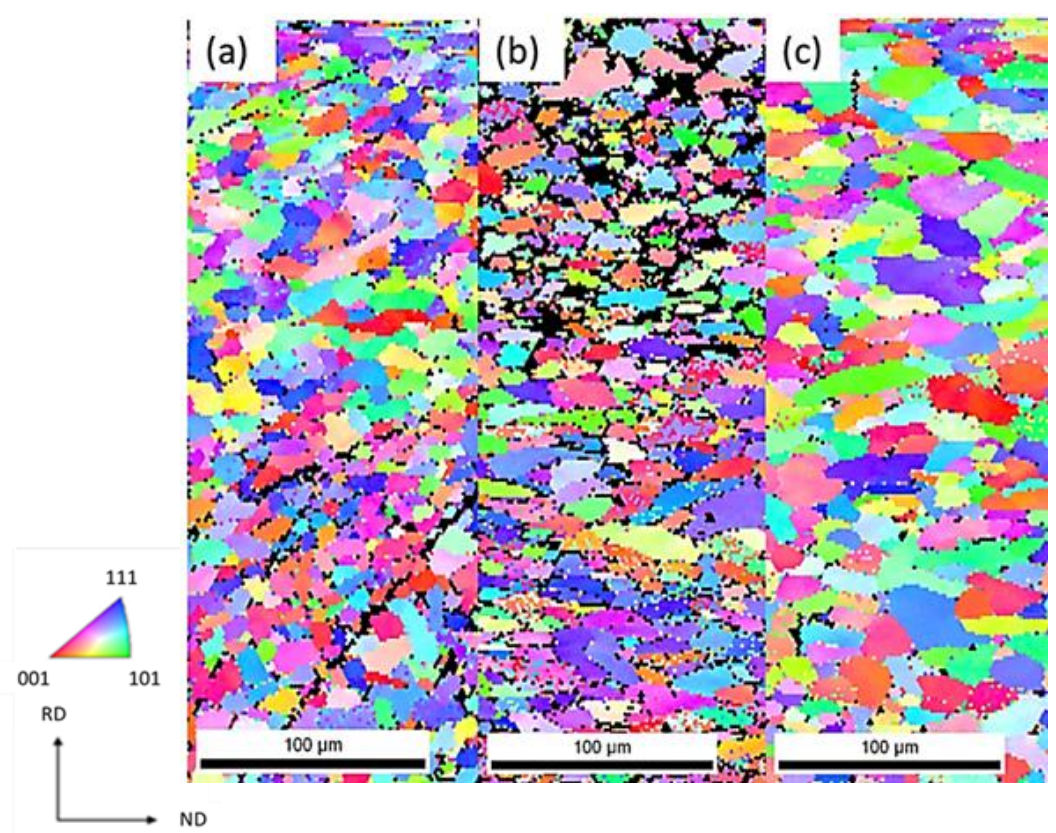

Figure 2: OIM maps in the analyzed steel specimen (a) without TT; (b) $900 \mathrm{~s}$; (c) $1800 \mathrm{~s}$.

Figure 3 shows the evolution of the textures of the specimen subjected to the aforementioned bending before and after annealing for $900 \mathrm{~s}$ and $1800 \mathrm{~s}$, using orientation density function plots components in $\varphi 2=$ $45^{\circ}$ section of ODF representing main orientation.

After deformation, the specimen presents a preferential $\gamma$ fiber texture, figure 3(a), After $900 \mathrm{~s}$ of annealing, there is an significant increase in $\gamma$ fiber with $\{111\}$ typical of a steel which has undergone deformation pronounced in its microstructure tensile (Figure 3 (b)). After $1800 \mathrm{~s}$ of heat treatment, there are no important changes in texture, as seen in figure 3(c).

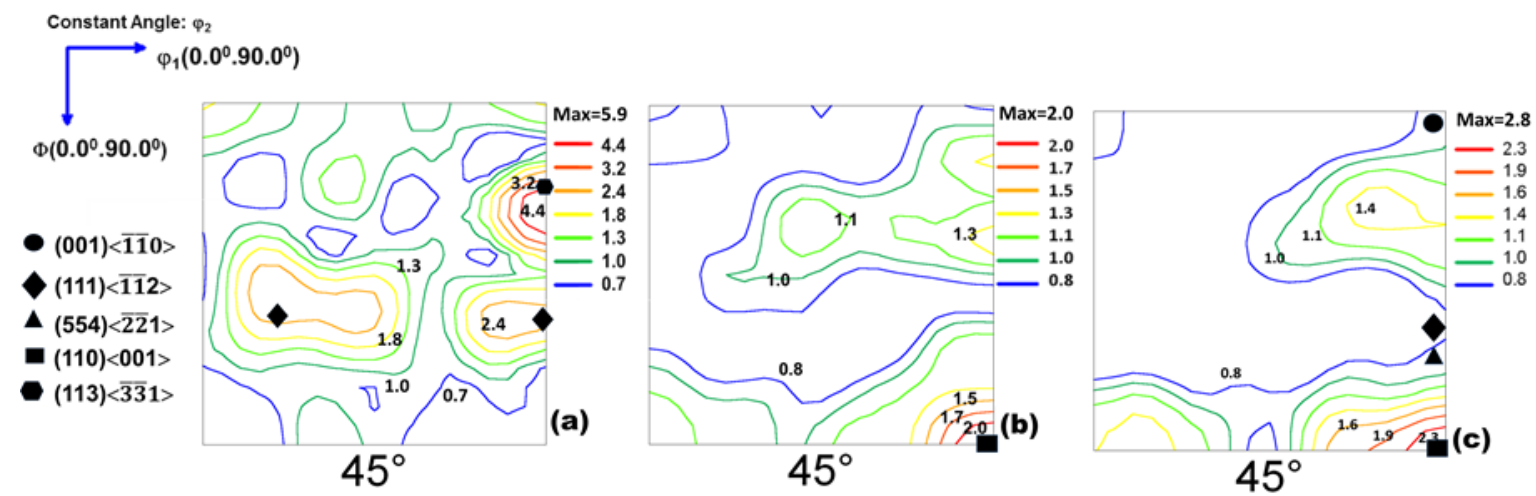

Figure 3: Anex components in $\varphi 2=45^{\circ}$ section of ODF representing main orientation. (a) without heat treatment; (b) $900 \mathrm{~s} ;$ (c) $1800 \mathrm{~s}$.

Figure 4 shows the evolution of the figure and the inverse pole figure of each of samples in Figure 4 (a) shows that the sample without heat treatment does not exhibit a preferred orientation pole. In contrast, the samples subjected to different heat treatments have a preferential orientation $\{111\}$, especially the sample under thermal treatment 1800 seconds (Figure 4 (c)). 


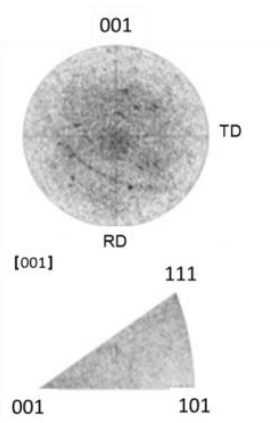

(a)

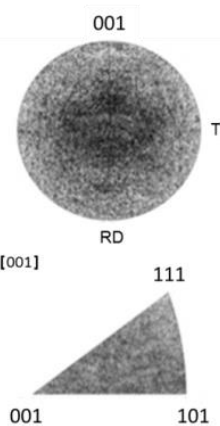

(b)

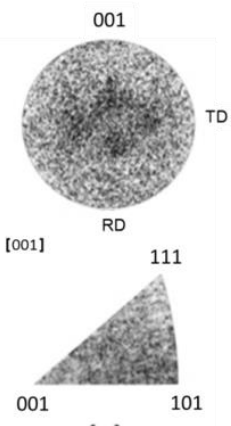

(c)

Figure 4: Pole and inverse pole figures (a) without heat treatment; (b) $900 \mathrm{~s}$; (c) $1800 \mathrm{~s}$.

In order to distinguish the differences between the tensile and compressive areas after annealing, local ODFs, pole figures and misorientation histograms were calculated in the tensile, compressive and central areas. Considering the 2 different stress states after bending between the external and internal bending areas (tension and compression), it was expected to detect changes in the crystallographic texture of these areas. Figure 5 shows texture evolution after annealing in the tensile, compressive and central area.

The ODF figures show an increase in the (111) [01 $\overline{1}] / / \mathrm{ND}$ after annealing in the tensile area after annealing. In contrast, the center area does not show important changes in texture after annealing. This is also reflected in figure 6, where pole figures for the 3 areas and annealing times are presented. It can be seen that the central area has no significant changes in texture, confirming that this area experienced no deformation. In contrast, there are interesting changes in the compressive area. In both figure 5 and 6 , it is possible to detect an increase in texture. In this particular area, there is a large increase in $\gamma$ fiber, which is more significant than the one found in the tensile region.

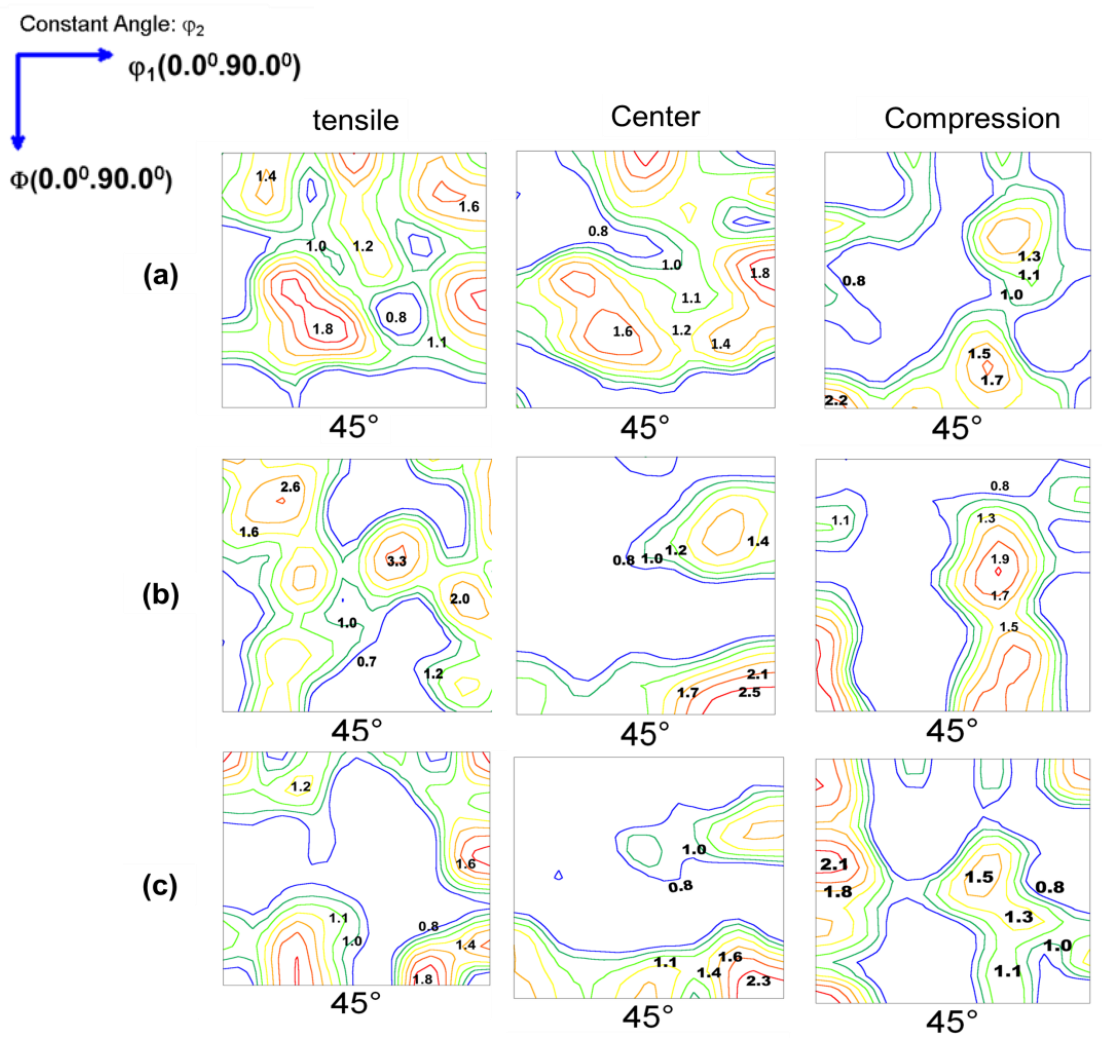

Figure 5: ODF's (a) without heat treatment (b) $900 \mathrm{~s}$; (c) $1800 \mathrm{~s}$. 
(a)

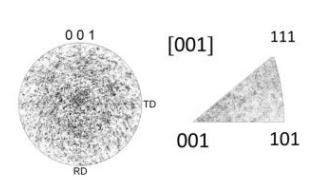

(b)

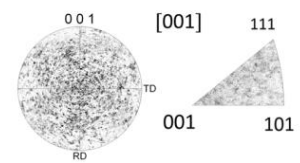

(c)

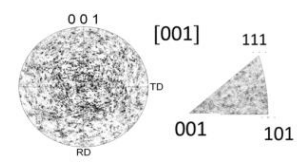

center
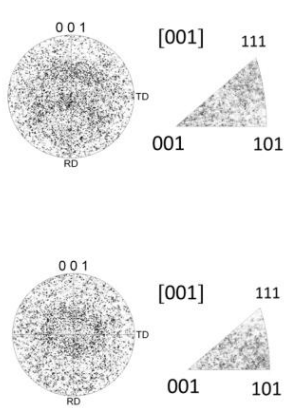

[001] 111

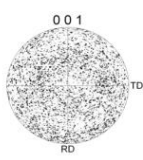

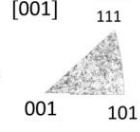

compression

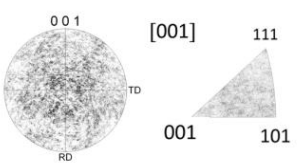

[001] 111

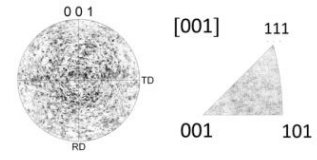

[001] 111

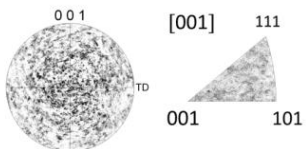

Figure 6: Pole and inversed pole figures (a) without heat treatment (b) $900 \mathrm{~s}$; (c) $1800 \mathrm{~s}$.

These findings were further analyzed through the use of misorientation histograms shown in figure 7. After deformation, the compressive area shows an important fraction of $0^{\circ}$ misorientation between grains. After annealing, this fraction is significantly reduced, while the fraction of misorientation above $30^{\circ}$ degrees is significantly increased. In contrast, the misorientation fractions for both the tensile and center area show no important changes.

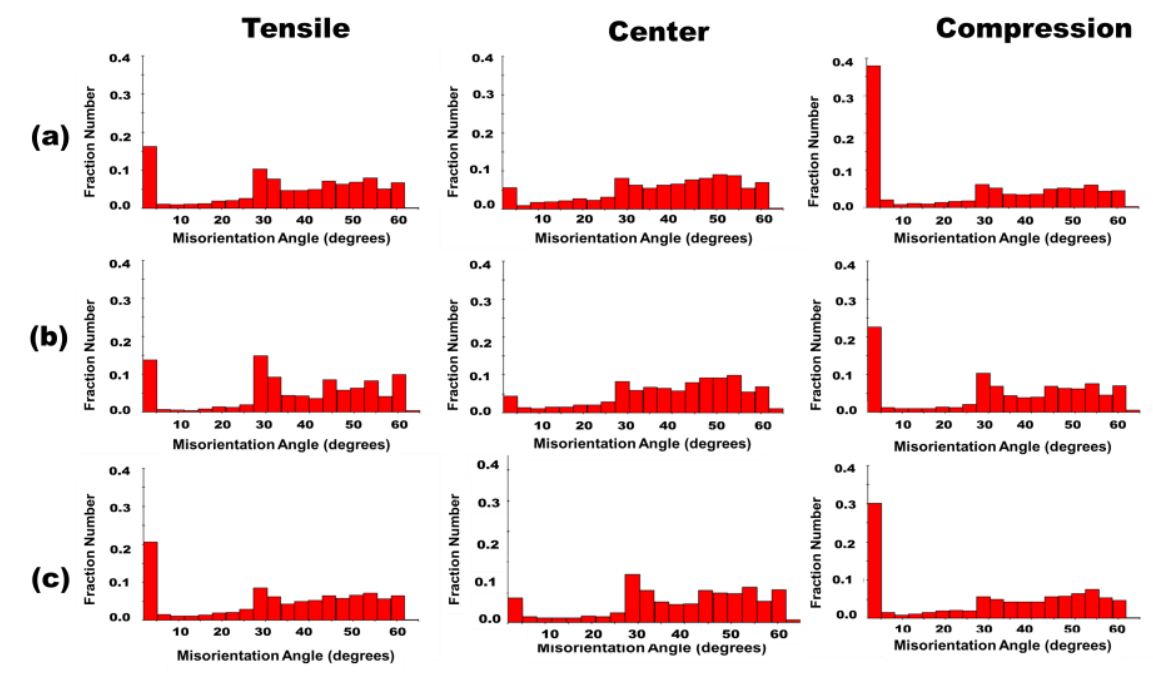

Figure 7: Misorientation histograms obtained from the samples (a) without heat treatment; (b) after $900 \mathrm{~s}$; (c) after $1800 \mathrm{~s}$.

\section{CONCLUSIONS}

EBSD is a very useful experimental tool for characterizing crystallographic textures. The results show that there are important differences in annealing textures between tensile and compression regions for this kind of steel. In particular the compressive area displays a more defined $\gamma$ fiber than the tensile area, which is more suited for deep stamping processes. By analyzing the ODFs and misorientation histograms it is possible to further understand these differences to obtain the required mechanical properties for subsequent processes. 


\section{ACKNOWLEDGEMENTS}

This work was carried out with the financial support of CONACYT. We also acknowledge the support of AHMSA for donating the materials analyzed in this study.

\section{BIBLIOGRAPHY}

[1] KANG Y., et al, "Texture Development in Low Carbon Sheet Steels for Automotive Application", Chapter 5, Microstructure and Texture in Steel and Other Materials, Jamshedpur India, pp. 85-100, Feb. 2008.

[2] DOHERTY R.D., D.A. HUGHES, HUMPHREYES F.J., et al., "Current issues in recrystallization: a review”, Materials sciencie \& Engineering. pp. 219-274, Abril 1997.

[3]RIOS, P.R., SICILIANO JUNIOR, F., SANDIM, H.R.Z, et al., "Nucleation and Growth during Recrystallization", Materials Research, v. 8, n. 3, pp. 225-238, 2005.

[4] HUMPHREYES F.J., HATHERLY, M., "Recrystallization and relate Annealing Phenomena", Elsevier Oxford, pp. 177-178, 1995.

[5] ADEGBUYI, P.A.O, ATIRI, A. "The Effect of Annealing on the Microstructure of Mechanical Properties of a Rolled Steel Product", The Pacific Journal of Science and Technology, v. 10. n. 2, pp. 149-162, Nov. 2009.

[6] SALINAS, J., SALINAS, A., "Mechanism of grain growth during annealing of Si- Al electrical steel strips deformed in tension", MRS PROCEEDINGS, v. 1276, 2010.

[7] SCHINDLER J. P. et al. "Effect of cold rolling and annealing on mechanical properties of HSLA steel", Archivos de Ciencia de los Materiales e Ingeniería 36/1, pp. 41-47, 2009.

[8] LI, B.L., GODFREY, B.L., MENG, Q.C., et al. "Microstructural evolution of IF-steel during cold rolling", Acta Materialia Inc. Published by Elsevier 52, v.52,n.4, pp. 1069-1081, 2004.

[9] BERGSTRÖM, Y. "A dislocation model for the plastic deformation of single-phase alpha-iron", http://www.plastic-deformation.com/paper1.pdf , May 2010.

[10] CALLISTER, D. JR., "Fundamentals of materials science and engineering /an Interactive", Augusto 2000.

[11] OMARI, M.A., SEVOSTIANOV, I., "Evaluation of the growth of dislocations density in fatigue loading process", Department of Mechanical and Aerospace Engineering, New Mexico State University, Las Cruces, NM 88003, USA. Int. J Fract 179, pp. 229-235, 2013.

[12] MESA GRAJALES, D.H., "Principles and applications of the Electron Back-scattering Diffraction Technical (EBSD)", Informador Técnico (Colombia), v. 74. pp. 64 - 74, 2010.

[13] HUMPHREYES F.J., "Review Grain and subgrain characterisation by electron backscatter diffraction". Journal of materials science, v. 36, n.16, pp. 3833 - 3854, 2001.

[14] GODEC, M.J., "Presentation methods of textures measurements", En Materiali in Tehnoloije, v. 34, n.6, pp. 359-364, 2000.

[15] HANSEN, N., HUANG, X., KAMIKAWA, N., "Structure and Strength of IF Steel After Large Strain Deformation", chapter 3, In: Proceedings of the international conference on microstructure and texture in steels and other materials. Jamshedpur, India, pp. 33-42, 2008.

[16] HUITCHINSON, B. "Deformation microstructures and textures in steels", Phil. Trans. R. Soc., Lond. 357, DOI: 10.1098/rsta.1999.0385, published 15, pp.1471-1485, June 1999.

[17] JONAS J. "Transformation textures associated with steel processing", Chapter 1, In: Proceedings of the international conference on microstructure and texture in steels and other materials, Jamshedpur, India, pp. 3-16, 2008.

[18] WATANABE T., et al. "The Coming of Grain Boundary Engineering in the 21st Century", chapter 4, Microstructure and Texture in Steel and Other Materials, Jamshedpur India, pp. 48-73, Feb. 2008.

[19] VERBEKEN, K., KESTENS, L., JONAS, J.J. "Microtextural study of orientation change during nucleation and growth in a cold rolled", Scripta Materialia, v.48, n.10, pp. 1457-1462, 2003.

[20] RAABE, D., LUCKE, K. "Rolling and annealing textures of BCC Metals", Materials Science Forum Trans Tech Publications, Switzerland, pp. 157-162, 1994.

[21] DAVID, J., WRIGHT,S.I. "Electron Backscatter Diffraction in Materials Science", chapter 7, New York, Ed. Plenum Publishers, pp. 97-107, 2009.

[22] SAMADJAR, I., VERLINDEN, B., VAN HOUTTE, P., et al, " $\gamma$-Fibre recrystallization texture in IF- 
steel: an investigation on the recrystallization mechanisms", Materials Science and Engineering A, v. 238, n.2, pp. 343-350, 1997.

[23] KWSTENS, L., JONAS, J.J., VAN HOUTTE, P., et al, "Orientation Selective Recristallyzation of Nonoriened Electrical Steels", Metallurgical and Materials Transactions, v. 27A, pp. 2347-2358, Augusto 1996.

[24] WANG, Y.D., LIN PENG, R., WANG, X. L., et al., "Grain-orientation-dependent residual stress and the effect of annealing in cold-rolled stainless steel", Acta Materialia 50, pp. 1717-1734, 2002.

[25] KANG, Y.J., KIM, D.I., LEE, H.CH., chapter 5., Texture Development in Low Carbon Sheet Steels for Automotive Application, In: HALDAR, A., SUWAS, S., BHATTACHARJEE, D., Microstructure and Texture in Steels, () Springer, pp. 85-101, 2009.

[26] BHATTACHARJEE, P.P, ZAID, M., SATHIARAJ, G.D., et al., "Evolution of microstructure and texture during warm rolling of a duplex steel", Metallurgical and Materials Transactions, v. 45A, pp. 21802187, April 2014. 